Research Article

\title{
The Effect of Freeze-Thaw Damage on Corrosion in Reinforced Concrete
}

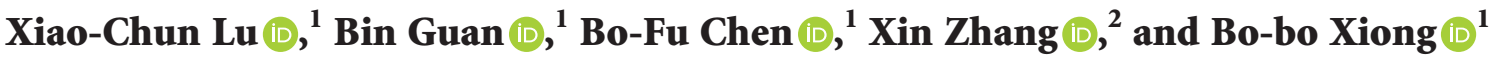 \\ ${ }^{1}$ College of Hydraulic and Environmental Engineering, Three Gorges University, Yichang, China \\ ${ }^{2}$ China Yangtze Power Co., Ltd., Beijing, China \\ Correspondence should be addressed to Bin Guan; 201908150021023@ctgu.edu.cn and Bo-Fu Chen; chenbofu@ctgu.edu.cn
}

Received 22 March 2021; Revised 3 May 2021; Accepted 4 May 2021; Published 15 May 2021

Academic Editor: Yanhu Mu

Copyright (C) 2021 Xiao-Chun Lu et al. This is an open access article distributed under the Creative Commons Attribution License, which permits unrestricted use, distribution, and reproduction in any medium, provided the original work is properly cited.

The existing studies of the corrosion of reinforced concrete have mainly focused on the interface area and chemical ion erosion, ignoring the specific service environment of the reinforced concrete. In this study, the effect of freeze-thaw damage was investigated via corrosion experiments under different freeze-thaw cycle conditions. Steel reinforcement corrosion mass, ultimate pull-out force, corrosion rate, and bond slippage were chosen as characteristic parameters in the experiments, and scanning electron microscopy (SEM) analysis was used to explain the mechanism of action of freeze-thaw damage on corrosion. The results showed that, under identical corrosion conditions, the mass of steel reinforcement corrosion and corrosion rate increased by $39.6 \%$ and $39.7 \%$ when comparing 200 freeze-thaw cycles to 0 cycles, respectively. The ultimate pull-out force and bond slippage after 200 freeze-thaw cycles decreased by $73 \%$ and $31 \%$, respectively, compared with 0 freeze-thaw cycles. In addition, SEM analysis indicated that microstructure damage caused by freeze-thaw cycles accelerated the corrosion reaction and decreased cementitious properties, leading to decreasing ultimate pull-out force and bond slippage. The effect of freeze-thaw cycles and steel reinforcement corrosion on the macro mechanical properties of concrete is not a simple superposition.

\section{Introduction}

Steel reinforcement corrosion (SRC) is one of the main causes of reinforced concrete damage, which is widely concerned in civil engineering $[1,2]$. SRC refers to the intrusion of external acid substances and reaction with $\mathrm{Ca}(\mathrm{OH})_{2}$ under the action of water and air, which results in the destruction of the steel passivation film and the damage of reinforced concrete $[3,4]$. Compared with other reinforced concrete structures, hydraulic concrete is more easily damaged because of its longterm contact with reservoir water $[5,6]$, occurring in concrete-face slabs of rockfill dams, diversion tunnels, and spillways [7]. In addition, the real service environment of hydraulic concrete is more complex, which is not only affected by SRC, but also freeze-thaw damage, chemical erosion, dry-wet damage, and other functions that accelerate the degradation of the hydraulic concrete $[8,9]$. Especially in cold regions, hydraulic concrete is highly susceptible to freezethaw cycles due to seasonal variations of temperature and nearly $100 \%$ of reinforced concrete structure in northeast China suffers from local or large-area freeze-thaw damage $[10,11]$. Freeze-thaw damage and SRC of reinforced concrete are common phenomena in cold regions.

Hydraulic concrete structures in contact with acidic water are susceptible to the chemical erosion due to the porousness of concrete [12]. The chloride and sulfate ions can transfer into pores and react with steel reinforcement passivation film, leading to damage and corrosion of reinforced concrete [13, 14]. According to Powers' classical hydrostatic pressure theory [15], freeze-thaw cycles lead to changes in the pore structure and ion transport properties of concrete at the micro level, producing microcracks that may accelerate ion transport and steel reinforcement corrosion rate. In general, the SRC caused by freeze-thaw damage will lead to the decrease of mechanical strength and the acceleration of corrosion rate in concrete structure $[16,17]$. Thus, the corrosion damage of reinforced concrete in cold regions is more complicated. 
In recent years, many studies focused on the effects of freeze-thaw damage and corrosion on the properties of reinforced concrete, including combined and alternate actions [18]. Ma et al. found that frost damage aggravates the rate and degree of rebar corrosion under freeze-thaw environments [19]. Wang et al. [20] studied the coupled effects of freeze-thaw cycling and chloride ions corrosion for steel reinforcement in concrete and found the serious spalling occurred with increasing freeze-thaw cycles. Berrocal et al. [21] investigated the corrosion of steel bars embedded in fibres reinforced concrete under chloride attack and found the fibres can suppress crack width in concrete. Zhang et al. [22] found the initial damage degree will accelerate the degradation rate of strength in reinforced concrete by investigating the influence of the degree of damage on the degradation of concrete under freeze-thaw cycles. For the corrosion characteristic parameters of reinforced concrete subjected to freeze-thaw cycles, Ji et al. [23] carried out experiments on the bonding properties of reinforced concrete under 50 freeze-thaw cycles by means of central pullout tests and found the effect of freeze-thaw damage on bond strength turns larger with the increase of the diameter of the test steel bar. He et al. [24] conducted beam bond failure tests to study the effect of freeze-thaw cycles and corrosion on bonding and slip performance of concrete and discussed the relationship between crack width and chloride ion erosion. Liu et al. [25] investigated the bond behavior between the RAC and the deformed steel bars after the freeze-thaw cycles and found the bond strength gradually decreased as the freeze-thaw cycles. Zhang et al. [26] studied the bonding performance of concrete and its reinforcements under freeze-thaw cycles and chloride ion corrosion. Besides, the effect of freeze-thaw damage on SRC depends on the evolution of microscopic properties in reinforced concrete. Sicat et al. [27] investigated the real-time deformational behavior of the interfacial transition zone (ITZ) in concrete during freeze-thaw cycles and found the ITZ exhibited higher deformation than the matrix and aggregate due to its higher porosity and weaker strength. Yao et al. [28] studied the microcrack evolution process of concrete subjected to freeze-thaw cycles and multisalt solution attack. Luo et al. [29] investigated the effect of cyclic freeze-thaw on the shear strength of new-old concrete interfaces.

All of the above research mainly focuses on bond properties (bond strength and bond slippage) of concrete and its steel reinforcement under different freeze-thaw cycles. However, the assessment index cannot fully reflect the effect of freeze-thaw damage on the steel reinforcement corrosion and the corrosion mass, corrosion ratio, and rate should be considered. Besides, the number of freeze-thaw cycles may not be enough to explain the effect of higher degree of freeze-thaw damage on SRC in reinforced concrete. The selected sample points in the microscopic experiment are limited, and the relationship between macroscopic properties and microstructure is not clear enough. In general, it is necessary to further study the effect of freeze-thaw cycles on SRC from a micro level. Understanding the failure mechanism of reinforced concrete under freeze-thaw cycles is also valuable for predicting concrete durability and changing the corrosion resistance of reinforced concrete in cold regions.

In this paper, the effect of freeze-thaw cycles on corrosion in reinforced concrete was investigated via steel reinforcement corrosion experiments. First, reinforced concrete samples were made and exposed to different freezethaw cycles. The index changes of the quality of steel reinforcement, interfacial bond slippage, and ultimate pull-out force were investigated by the central pull-out test. In addition, the mechanism of steel reinforcement corrosion and material properties were analyzed via scanning electron microscopy (SEM) of the concrete around the central point of the steel reinforcement. The experimental results are of great theoretical value and practical significance for durability evaluation and structural improvement of concrete structures during service life.

\section{Materials and Experimental Procedure}

To determine the influence of freeze-thaw cycles on the corrosion of reinforced concrete, a series of orthogonal experiments were designed with different freeze-thaw cycles and corrosion times. First, the specimens were exposed to different freeze-thaw cycles: $D_{0}$ (no freeze-thaw cycle), $D_{1}$ (50 freeze-thaw cycles), $D_{2}$ (100 freeze-thaw cycles), $D_{3}$ (150 freeze-thaw cycles), and $D_{4}$ (200 freeze-thaw cycles). Then, different electrochemical-accelerated steel-reinforcement corrosion processes were performed on the specimens: $X_{0}$ (no corrosion), $X_{1}(5.85 \mathrm{~d}), X_{2}(15.6 \mathrm{~d})$, and $X_{3}(23.4 \mathrm{~d})$, with the corrosion times from $X_{0}$ to $X_{4}$ corresponding to $0 \%, 3 \%$, $8 \%$, and $12 \%$ of the theoretical corrosion ratio, respectively.

2.1. Materials and Specimen Preparation. Granite gravel (size ranges of $5-20 \mathrm{~mm}, 20-40 \mathrm{~mm}$ ), river sand (fineness modulus of 2.4-2.7), PO42.5-type Portland cement, and Class-I fly ash were used to make the specimens. Additives were included, including a highly efficient naphthalene water-reducing agent and an air-entraining agent, with the mixture proportion of the concrete shown in Table 1. Test specimens consisted of HRB335 screw-thread steel with a diameter of $20 \mathrm{~mm}$ and a length of $400 \mathrm{~mm}$ embedded into the center of concrete, with the length, width, and depth of the concrete being $100 \mathrm{~mm}, 100 \mathrm{~mm}$, and $200 \mathrm{~mm}$, respectively. In addition, unbonded segments on both ends of the specimens were obtained using PVC pipe, and the annular space between the steel reinforcement and the PVC tube was filled with polyurethane foam to avoid concrete flowing into it during the casting procedure. Before casting the specimen, the unbonded segments of steel reinforcement were brushed with epoxy resin for anticorrosion purposes. The specimens were removed from their molds after $72 \mathrm{~h}$ and stored for $90 \mathrm{~d}$ at $25^{\circ} \mathrm{C}$ and $98 \%$ relative humidity. The Chinese standards for steel ("Steel for the Reinforcement of Concrete-Part 2: Hot Rolled Ribbed Bars") and design code for concrete-face rockfill dams $[30,31]$ were referred to for specimen preparation. A detailed size of the specimen is shown in Figure 1. 
TABle 1: Mix proportions concrete $\left(\mathrm{kg} / \mathrm{m}^{3}\right)$.

\begin{tabular}{lcccccccc}
\hline Water-cement ration & Wsp (\%) & Water & Cement & Fly ash & Sand & Aggregate & Water-reducing agent & Air-entraining agent \\
\hline 0.4 & 0.3 & 11.7 & 279.2 & 85 & 553.2 & 1290.8 & 1 & 0.02 \\
\hline
\end{tabular}

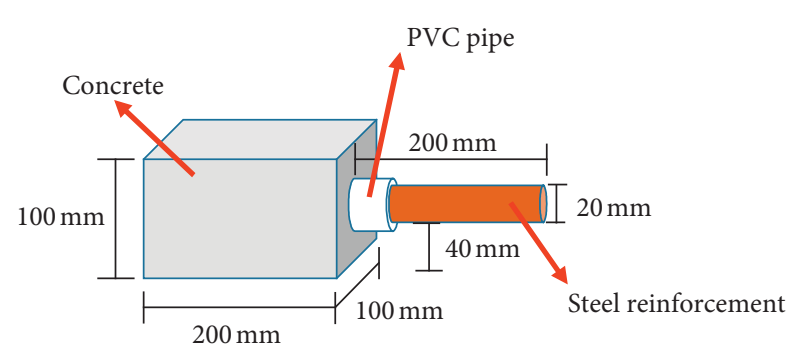

Figure 1: Details of stereoscopic specimen.

2.2. Experimental Procedure. The experimental procedure included the freeze-thaw cycle process, accelerated corrosion process, and measuring details. The macroscopic parameters of measurement included the mass of corrosion, corrosion rate, pull-out force, and bond slippage. The microscopic parameters of measurement included scanning electron microscopy (SEM) and porosity, which was obtained by the water absorption method [32]. The general testing procedure is shown in Figure 2.

2.2.1. Freeze-Thaw Cycles Process. The specimens were immersed in water for $4 \mathrm{~d}$ before the freeze-thaw tests were carried out, which aimed to make the concrete in a watersaturated state. The freeze-thaw cycle tests were performed with a freeze-thaw machine (type TR-TSDRSL) according to Chinese code GB/T 50082-2009 [33]. In each freeze-thaw cycle, the temperature of the control specimen decreased from $8^{\circ} \mathrm{C} \pm 2^{\circ} \mathrm{C}$ to $-17^{\circ} \mathrm{C} \pm 2^{\circ} \mathrm{C}$ and then increased back to $8^{\circ} \mathrm{C} \pm 2^{\circ} \mathrm{C}$ within $4 \mathrm{~h}$. During the test, specimens were taken out for inspection after 50 freeze-thaw cycles. After reaching a predefined number of freeze-thaws $(n=0,50,100,150$, and 200), the specimens were removed from the machine. At the same time, key parameters such as the ultimate pull-out force and bond slippage were measured for comparison after the accelerated corrosion experiment. Finally, the steel reinforcement corrosion tests, central pull-out tests, and SEM tests were carried out.

2.2.2. Accelerated Corrosion Process. Accelerated corrosion tests were carried out similarly to the freeze-thaw cycle tests. The specimens were dried in a ventilated oven at a temperature of $50^{\circ} \mathrm{C}$ until they reached constant weight for calculating the extent of the steel reinforcement corrosion. In general, electrochemical-accelerated-corrosion speeds up the chloride ions corrosion process and ensures accuracy for the test results [34]. To eliminate the influence of humidity on concrete resistance and chloride ions transporting rates, this test adopted the full immersion method [35]. The specimens were kept in an aqueous salt solution containing $5 \% \mathrm{NaCl}$ to start the accelerated steel reinforcement corrosion test. The anode of a direct current (DC) regulated power supply was connected to the steel, while the cathode was connected to a copper sheet immersed in $\mathrm{NaCl}$ solution in parallel mode. Through the electrolysis reaction, the anode electron loss led the steel surface to generate $\mathrm{Fe}^{2+}$, which reacted with water in the solution to generate rust. The $50 \mathrm{~mA}$ was applied to accelerate the corrosion process; the total corrosion time was $5.85 \mathrm{~d}$ ( $3 \%$ theoretical corrosion ratio), $15.6 \mathrm{~d}$ ( $8 \%$ theoretical corrosion ratio), and $23.4 \mathrm{~d}$ (12\% theoretical corrosion ratio), respectively.

2.2.3. Measuring Details. To investigate the effect of freezethaw and corrosion on bond behavior, the bond strength and load characteristic parameters were measured by central pull-out experiments based on the Chinese Code of Standard for test methods of concrete structures GB/T 50152-2012 [36]. The pull-out test used a WAW-Y1000 C microcomputer-controlled electrohydraulic servo universal testing machine and the loading rate was $0.2 \mathrm{kN} / \mathrm{S}$ to $500 \mathrm{kN} / \mathrm{S}$. The failure mode of all the specimens was attributed to splitting failure. The experiment was loaded from $0 \mathrm{kN}$ until the reinforced concrete specimen was destroyed and a displacement sensor was set on the loading end of the central pull-out specimens to measure the bond slippage $(\mathrm{mm})$ of the loading end.

The corroded steel reinforcements were taken out when the pull-out test was completed and were then cleaned with $5 \% \mathrm{HCl}$ solution and neutralized with $\mathrm{Ca}(\mathrm{OH})_{2}$ solution. The specimens were flushed with clean water and placed into a drying device at $20^{\circ} \mathrm{C}$ for $4 \mathrm{~h}$. The mass of the steel reinforcements was weighed by electronic scales with an accuracy of $0.01 \mathrm{~g}$. The steel reinforcement corrosion ratio was calculated with

$$
W_{n}=\frac{G_{0}-G_{n}}{G_{0}} \times 100 \%
$$

where $G_{0}$ is the mass of the steel reinforcement before the freeze-thaw test (g), $n$ is the number of freeze-thaw cycles, $G_{n}$ is the mass of the steel reinforcement after $n$ cycles of freezethaw $(\mathrm{g})$, and $W_{n}$ is the actual corrosion ratio of the steel reinforcement (\%).

The macroscopic mechanical properties of reinforced concrete, such as the ultimate pull-out force and bond slippage, were determined from internal microstructure characteristics. The purpose of the SEM tests was to reveal the effect of freeze-thaw cycles on the microstructure of reinforced concrete from a micro level and then to reveal the mechanism of freeze-thaw cycles on steel reinforcement corrosion. Thus, to obtain the microstructure evolution of concrete (after varied freeze-thaw cycles) throughout the corrosion process, several measuring points were chosen; from the surface to the interior, the points were defined as the central point, the internal point, and the edge point. In addition, the sample's central point was taken from the 


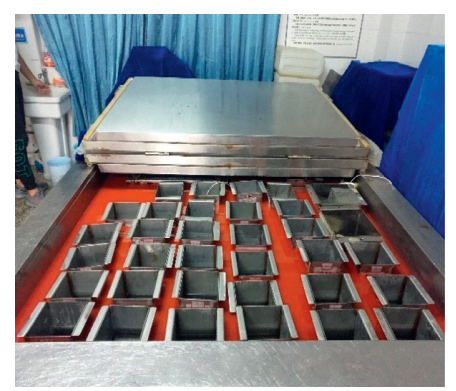

(a)

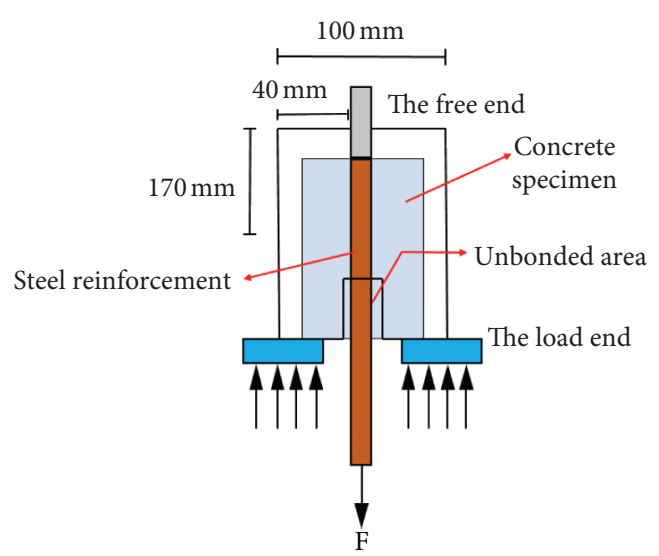

(d)

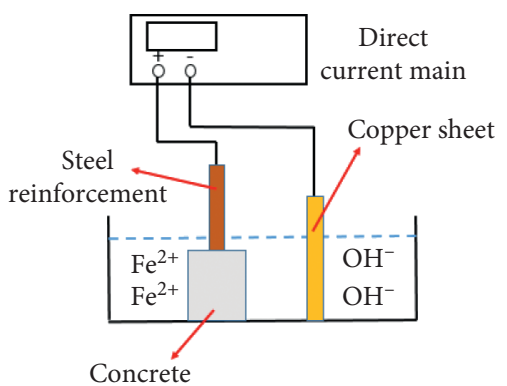

(b)

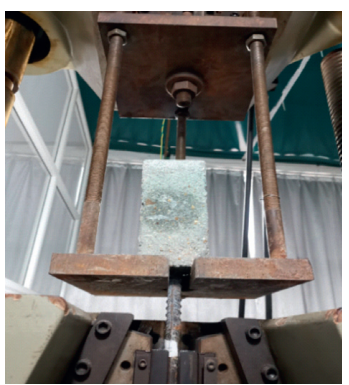

(c)

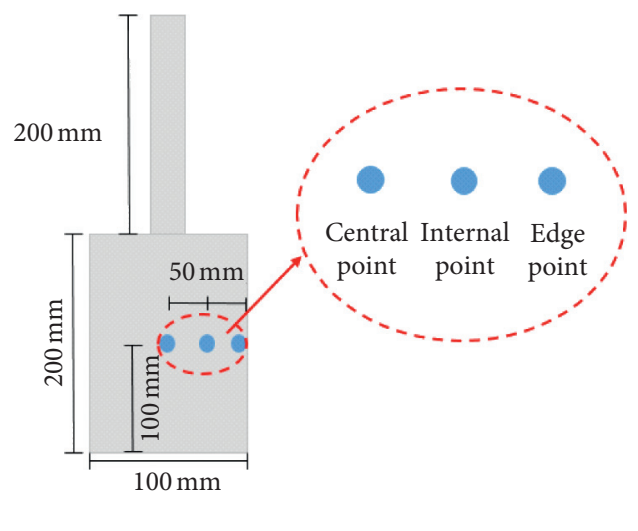

(e)

Figure 2: Flow diagram of the experiment. (a) Freeze-thaw test. (b) Accelerated steel corrosion test. (c) Pull-out test loading process. (d) Schematic diagram of the steel reinforcement pull-out test. (e) Samples and points for porosity measurement (mm).

center of the bonding segment between the steel reinforcement and the concrete. The samples (about $1 \mathrm{~mm}$ thick, $3 \mathrm{~mm}$ long, and $3 \mathrm{~mm}$ wide) were cut from the cross section of the specimen by a diamond saw. A JEOLO JSM 7500F SEM was used to observe the microstructure with an optimal resolution of $1 \mathrm{~nm}(15 \mathrm{kv})$. In addition, the samples were treated with high-pressure gold spray before testing for highquality imaging.

\section{Experimental Results}

3.1. Surface Change. The corrosion state and surface corrosion cracks can arguably reflect the effect of freeze-thaw cycles on steel reinforcement corrosion. The surface change of a reinforced concrete specimen is shown in Figure 3, and the differences of surface change under different freeze-thaw cycles are obvious. Naturally, more corrosion products were produced by the increasing number of freeze-thaw cycles.

The surface of specimens not subjected to freeze-thaw changed only slightly after $5.85 \mathrm{~d}$ (3\% theoretical corrosion ratio), and the edge of the specimens peeled off after $15.6 \mathrm{~d}$ ( $8 \%$ theoretical corrosion ratio). The surface color of the specimens subjected to 100 freeze-thaw cycles deepened, and large areas of the steel reinforcement in the bond section of the specimen began to rust after $5.85 \mathrm{~d}$ (3\% theoretical corrosion ratio). It is difficult to generate expansion cracks before lower freeze-thaw cycles because the entrained air bubbles can reduce the expansion stress of freezing water.
Notably, the specimen suffered from corrosion cracking after $23.4 \mathrm{~d}$ ( $12 \%$ theoretical corrosion ratio). For the specimen subjected to 200 freeze-thaw cycles, the mortar on its surface completely fell off, and the concrete at the edge was severely peeled after $15.6 \mathrm{~d}$ ( $8 \%$ theoretical corrosion ratio). Corrosion cracks with larger widths can be seen on the surface of specimens after $23.4 \mathrm{~d}$ (12\% theoretical corrosion ratio). With increased corrosion time, the surface damage of the specimens was very serious, and a large number of $\mathrm{Fe}(\mathrm{OH})_{3}$ had accumulated. In general, corrosion time had a significant impact on the damage process of the specimens. After the same number of freeze-thaw cycles, higher initial corrosion times led to more serious degradation; the reason for this is that micro cracks in the concrete caused by freeze-thaw cycles increased the corrosion expansive pressure and accelerated steel reinforcement corrosion, which produced even more micro cracks. Therefore, with increasing numbers of freeze-thaw cycles, it became easier for internal corrosion products to transfer into the exterior.

\subsection{Corrosion Behavior}

3.2.1. Mass of Corrosion. The mean corrosion extent of the specimens after varied freeze-thaw cycles is shown in Figure 4. The mass of corrosion in steel reinforcement continuously increased with increased corrosion times. After 23.4 corrosion times ( $12 \%$ theoretical corrosion ratio), the 

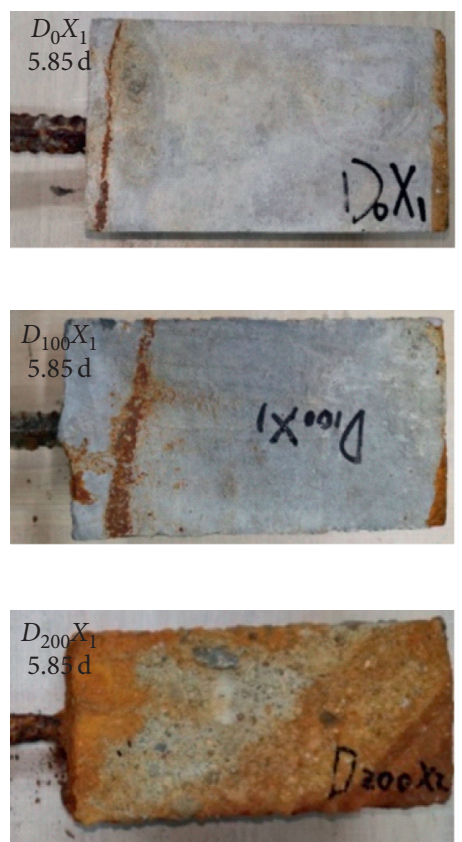

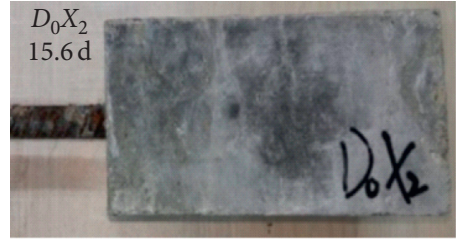

(a)

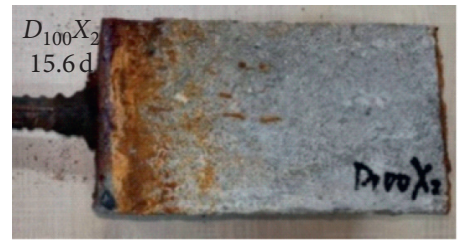

(b)

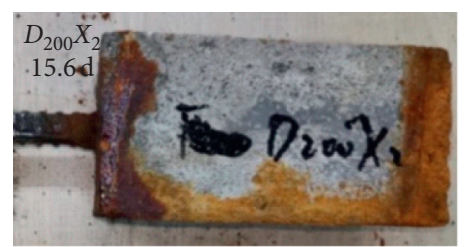

(c)
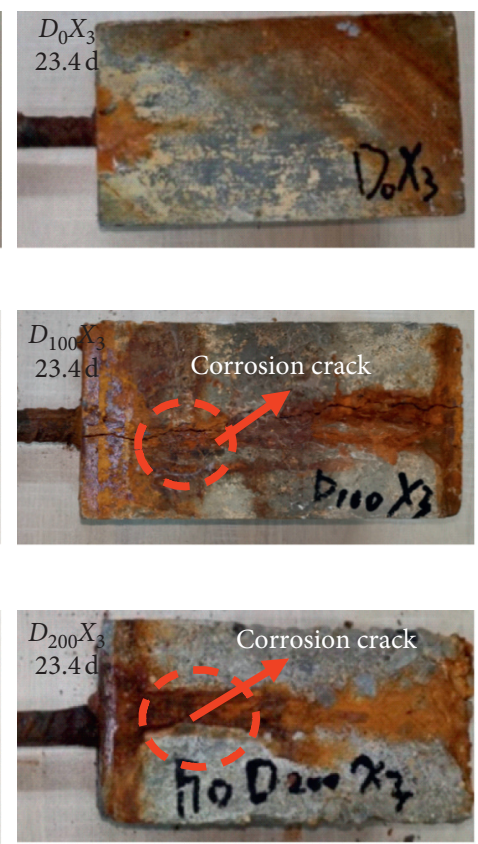

FiguRE 3: Surface changes of specimens under different freeze-thaw cycles. (a) 0 cycles of freeze-thaw. (b) 100 cycles of freeze-thaw. (c) 200 cycles of freeze-thaw.

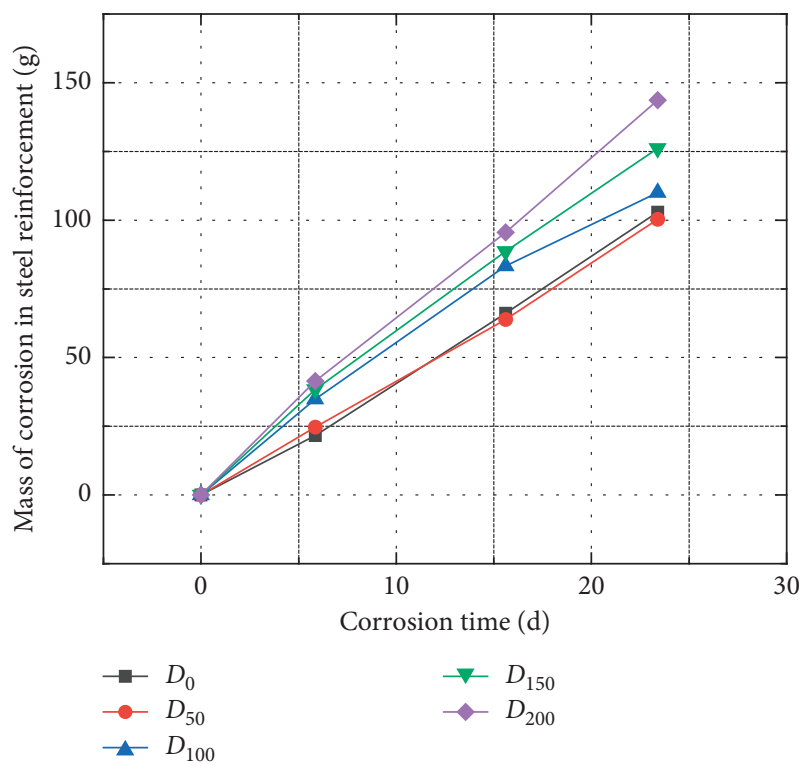

Figure 4: The mass change of steel reinforcement after varied corrosion times.

final corrosion mass of the specimens corresponding to 0,50 , 100,150 , and 200 freeze-thaw cycles was $102.9 \mathrm{~g}, 100.352 \mathrm{~g}$, $110.054 \mathrm{~g}, 126.126 \mathrm{~g}$, and $143.688 \mathrm{~g}$, respectively. The significant difference in corrosion mass of the steel reinforcement after 0 freeze-thaw cycles $(102.9 \mathrm{~g})$ and 200 freezethaw cycles ( $143.688 \mathrm{~g}$ ) is attributed to micro cracks in the concrete caused by freeze-thaw cycles increasing the transport properties of water and ions, which accelerates the corrosion reaction. Therefore, the more freeze-thaw cycles, the easier it is for external water molecules and chloride ions to transfer into the interior of the specimen.

3.2.2. Corrosion Rate. Figure 5 shows the relationship between the actual corrosion ratio and the number of freezethaw cycles. The theoretical corrosion ratios of steel reinforcement, $X_{0}, X_{1}, X_{2}$, and $X_{3}$, are compared with the actual corrosion ratios of steel reinforcement, $Y_{0}, Y_{1}, Y_{2}$, and $Y_{3}$. It could be observed the actual corrosion ratio was lower than the theoretical corrosion ratio before 100 freeze-thaw cycles due to differences in both chloride consumption and specimen casting in the experiment. It is clear that the deviation of the actual and theoretical corrosion ratios was not large. After 100 freeze-thaw cycles, the difference between the actual corrosion ratio and theoretical corrosion ratio increases. The higher the corrosion ratio, the steeper the curve becomes, corresponding to a faster corrosion ratio of the specimen. The deviation of the corrosion ratio of $X_{3}$ and $Y_{3}$ for 200 freezethaw cycles was 0.0266 , which is significantly higher than the deviation of $X_{3}$ and $Y_{3}(0.0087)$ after 150 freeze-thaw cycles. This is due to the permeability coefficient of the chloride ions and the specific resistance both decreasing with increased numbers of freeze-thaw cycles, resulting in generating a large amount of $\mathrm{Fe}(\mathrm{OH})_{3}$. Thus, the actual corrosion ratio exceeded the theoretical corrosion ratio.

Figure 6 shows the relationship between actual corrosion rate and corrosion time. The corrosion rate of the specimens increased with the number of freeze-thaw cycles before the $5.85 \mathrm{~d}$ mark ( $3 \%$ theoretical corrosion ratio). However, the increased rate varied with different numbers of freeze-thaw cycles, and the corrosion rate of the steel was significantly accelerated after 50 cycles. The corrosion rate was 


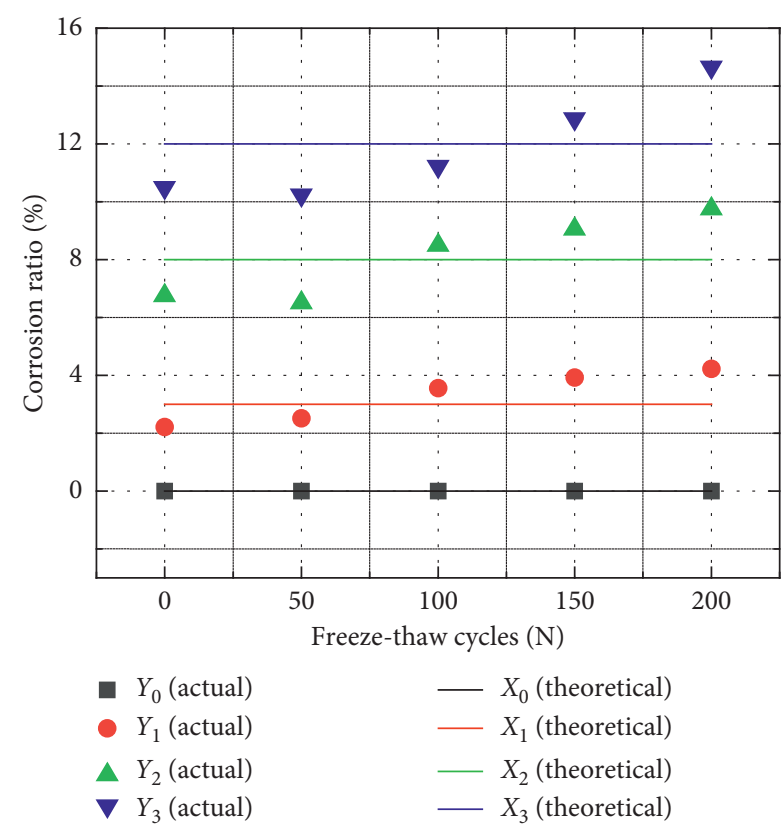

Figure 5: The difference between the actual corrosion ratio and theoretical corrosion ratio.

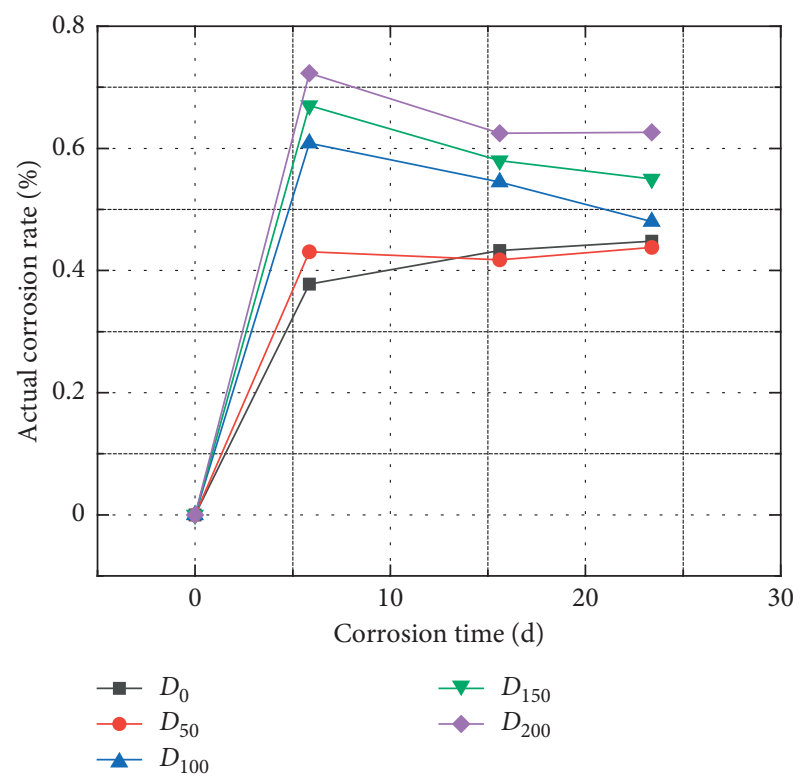

FIgURE 6: The change of corrosion rate in different corrosion times.

particularly similar within the initial corrosion time. The corrosion rate of the specimens decreases after $5.85 \mathrm{~d}$ (3\% theoretical corrosion ratio) because of the accumulation of corrosion products. When the corrosion time reaches the $23.4 \mathrm{~d}$ (12\% theoretical corrosion ratio), the corrosion rate at 200 cycles increased by $0.6 \%$, a $0.2 \%$ increase compared to 100 cycles $(0.4 \%)$. This indicated that the generated corrosion products decreased the transport property of chloride ions, resulting in a slower corrosion ratio. The combined action of the two effects led to the freeze-thaw cycles having a significant effect on steel reinforcement corrosion.

\subsection{Bond Behavior}

3.3.1. Ultimate Pull-Out Force. The ultimate pull-out force at various corrosion times is illustrated in Figure 7. The pullout force decreased rapidly with increasing numbers of corrosion times, especially within the initial corrosion time (5d), where the pull-out force was still high since the corrosion products $\left(\mathrm{Fe}(\mathrm{OH})_{3}\right)$ improved the roughness of the specimen and enhanced the frictional resistance at the reinforced concrete interface. However, the effect of freezethaw on the pull-out force became obvious when the corrosion time reached $23.4 \mathrm{~d}$ ( $12 \%$ theoretical corrosion ratio), where the pull-out force for 0 and 200 freeze-thaw cycles decreased by $36.2 \%$ and $75.5 \%$, respectively. By comparison, the decrease in ultimate pull-out force for 200 freeze-thaw cycles was higher than that in 0 freeze-thaw cycles. It was obvious that the freeze-thaw cycles had a significant impact on the pull-out force of reinforced concrete. The phenomenon can be explained as follows: freeze-thaw damage decreased the strength of concrete while increasing the corrosion ratio, which led to an acceleration of the corrosion process. Thus, the influence of freeze-thaw damage and corrosion on the pull-out force of reinforced concrete was not a simple superposition problem.

3.3.2. Bond Slippage. Figure 8 shows the relationship between the bond slippage and corrosion time. It can be observed that the bond slippage of all specimens decreased with increasing corrosion time, yet it remained constant after 15.6 days ( $8 \%$ theoretical corrosion ratio). During corrosion, increasing freeze-thaw cycles lowered the bond slippage. For specimens with freeze-thaw cycles of 0, 50, 100, 150 , and 200 cycles, the bond slippage after corrosion (15.6 d) decreased by $16.42,8.515,4.9,5.414$, and $4.859 \mathrm{~mm}$, respectively. The bond slippage decreased by $42.5 \%$ after 200 freeze-thaw cycles compared with specimens with 0 freezethaw cycles. From 0 cycles to 50 cycles, the bond slippage decreased by $9 \mathrm{~mm}$ for uncorroded specimens. However, the bond slippage of uncorroded specimens after 100 freezethaw cycles decreased by $2.05 \mathrm{~mm}$ compared with those subjected to 50 freeze-thaw cycles, decreased by $2 \mathrm{~mm}$ after 150 cycles compared with 100 cycles, and decreased by $1.38 \mathrm{~mm}$ after 200 cycles compared with 150 cycles. According to the results discussed in Section 3.2.1, this phenomenon was due to freeze-thaw damage accelerating corrosion and producing more corrosion products, which increased the corrosion expansive pressure and made damage more serious. Thus, the effect of freeze-thaw cycles on the bond slippage had already occurred prior to corrosion because the freeze-thaw cycles changed the mechanical properties of the concrete.

3.4. Porosity Analysis. The influence mechanism of freezethaw cycles on steel reinforcement corrosion was further explained by analyzing the change of porosity and the relationship between porosity and freeze-thaw cycles under different corrosion ratios. 


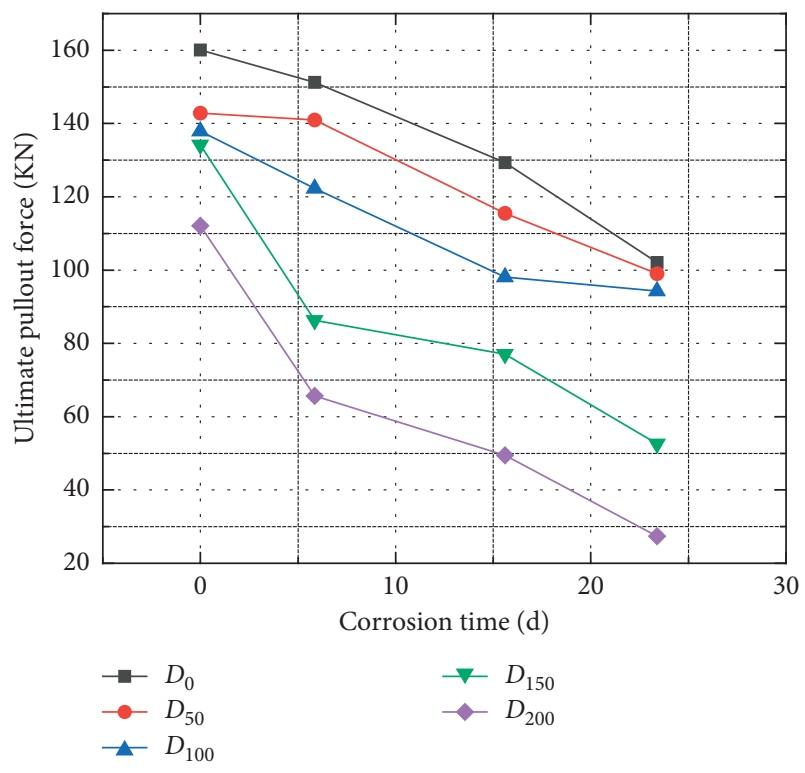

Figure 7: The change of ultimate pull-out force of steel reinforcements.

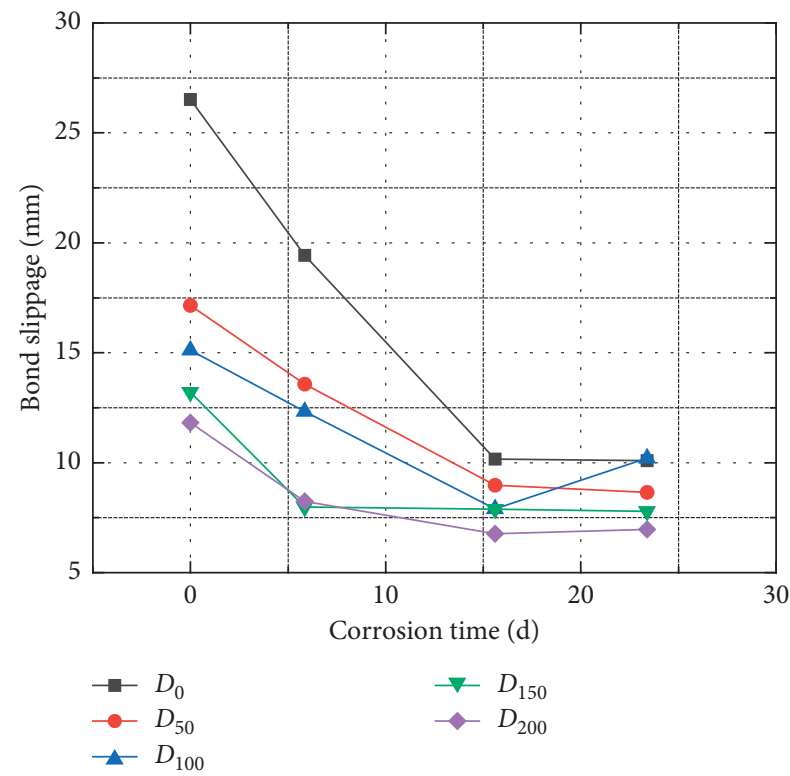

FIgURE 8: The change of bond slippage.

Figure 9 shows that porosity increased with increased numbers of freeze-thaw cycles. It can be observed that the slope of the curve in the ascending section of the edge point is larger than that of the internal point, and the ascending section of the central point is less sloped than the internal point. This showed that the freeze-thaw cycles had a significant influence on porosity from the surface to the center of the specimen. After 200 cycles, the concrete spalling deepened, and the overall structural performance was damaged. This was because the increased porosity of the edge point caused by freeze-thaw accelerated the corrosion ratio, which affected the bonding properties of the reinforced concrete.

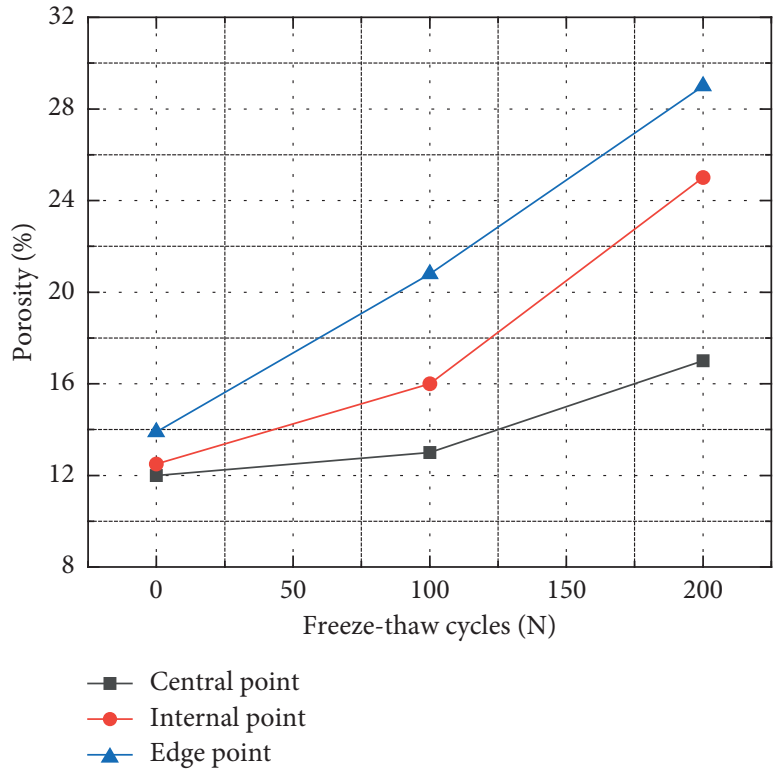

FIgURE 9: The effect of freeze-thaw cycles on the porosity of uncorroded specimens.

Figure 10 shows that the porosity of the $12 \%$ theoretical corrosion ratio group increased by $20 \%$ compared with the uncorroded group after the same number of freeze-thaw cycles. The porosity of the central point was especially greater than other positions in the initial freeze-thaw cycle. This was because the corrosion products caused damage in the central concrete but did not extend any further. The porosity of the internal point and edge point increased significantly with increasing numbers of cycles. After 100 cycles, the porosity of the edge point was greater than the central point, since the freeze-thaw cycles caused an increase in both porosity and cracks; the corrosion products developed from the center to the surface of the specimens. Both the freeze-thaw damage and corrosion made the cracks more serious, wherein the bond behavior of the reinforced concrete was almost lost. In summary, the change of porosity was related to the strength of concrete and affected the pullout force. Additionally, the increased porosity caused by freeze-thaw also affected the transport properties of chloride ions, which accelerated the corrosion reaction.

3.5. SEM Analysis. According to the above macroscopic testing results, the freeze-thaw cycles had a significant impact on steel reinforcement corrosion. In order to further explore the effect of freeze-thaw cycles on corrosion from a microscopic perspective, the testing groups with the greatest difference among all specimens (0 cycles and 200 cycles) were selected, and SEM images before and after corrosion were compared.

3.5.1. Uncorroded Group. The pore structure of uncorroded specimens with two levels of freeze-thaw cycles is clearly observed in Figure 11 (2000x magnification). In Figure 11(a), the internal hydration of the concrete was 


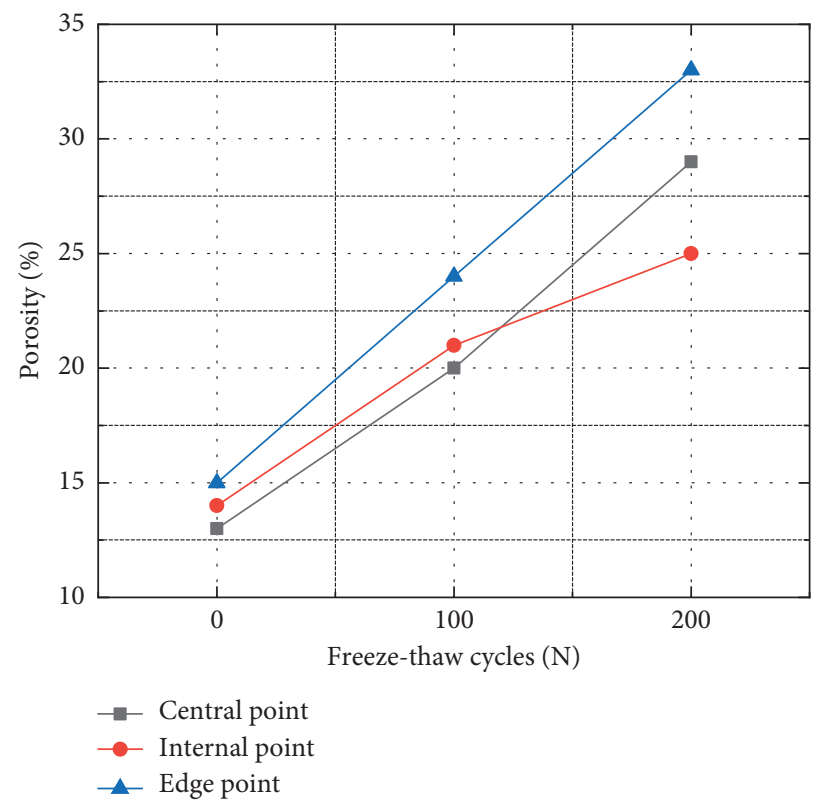

Figure 10: The effect of freeze-thaw cycles on the porosity of $12 \%$ theoretical corrosion ratio specimens.
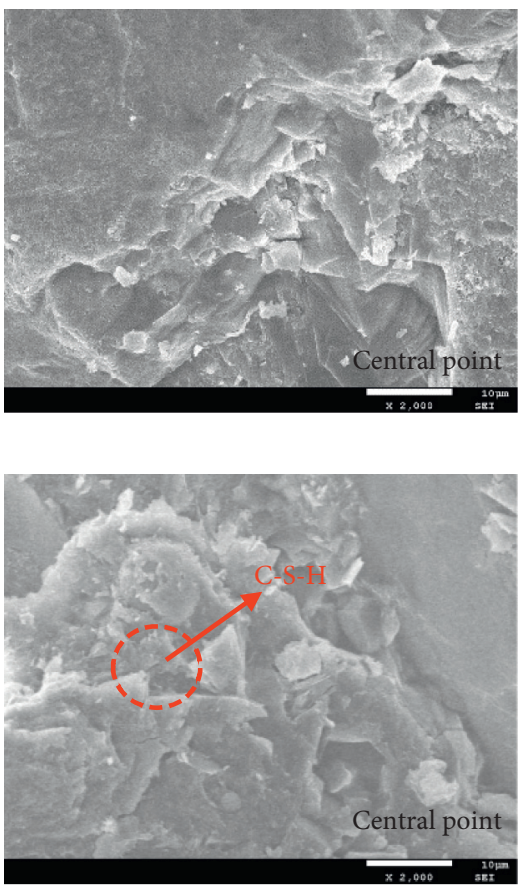

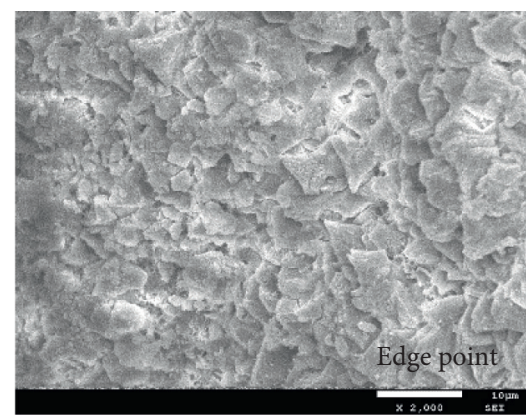

(a)
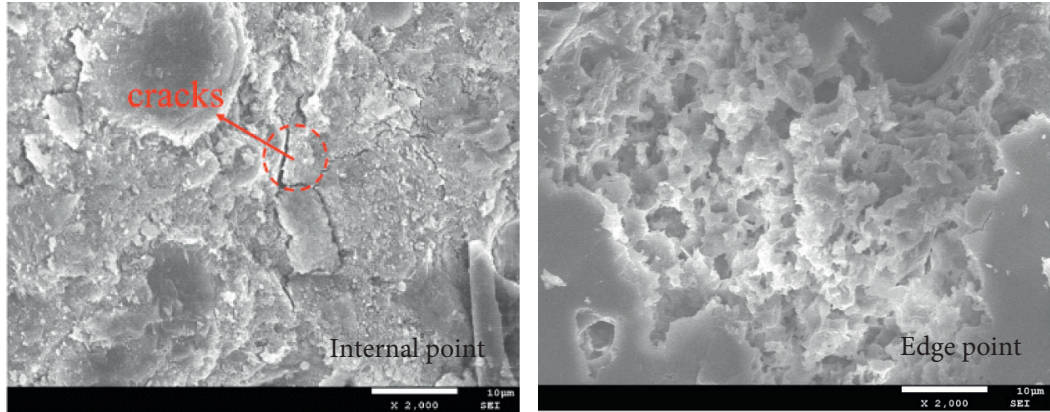

(b)

Figure 11: Electron microscope scanning of the uncorroded group. (a) 0 cycles of freeze-thaw without corrosion group. (b) 200 cycles of freeze-thaw without corrosion group.

complete, and the smooth and dense C-S-H structure occurred in all three positions. The overall structures in the concrete were very dense and the pores were small, and some fly ash particles could also be observed on the central point. Because fly ash was in cement paste, cement hydration was also involved in the hydration reaction, generating some calcium silicate hydrate gel.

Figure 11(b) shows the internal microstructure of uncorroded specimens after 200 freeze-thaw cycles. Compared with specimens without any cycles, the sample 
structure of the edge points became loose. Meanwhile, the internal and central positions were also damaged to varying levels. Some small cracks continued to expand and connect to form large cracks after 200 cycles, which had a serious impact on the material's structure.

After 200 freeze-thaw cycles, the edge point damage was greater than that of the internal point, and the damage of the internal point was greater than the central point. The path of freeze-thaw damage was from the surface to the interior. The pull-out force (Figure 7) and bond slippage (Figure 8) after 200 cycles were lower than those with 0 cycles. This was because the specimens exposed to freeze-thaw developed larger internal porosity and a looser structure, which led to a decrease in pull-out force and bond slippage.

3.5.2. Corroded Group. The pore structure of corroded specimens $(23.4 \mathrm{~d})$ exposed to two levels of freeze-thaw cycles is shown in Figure 12. Figure 12(a) shows that the surface of the edge point was smooth, dense, and without cracks. However, the internal point and central point changed significantly. The pores were relatively small and uniformly distributed in the internal point, but the number of pores and cracks increased in the central point. This was because the higher corrosion ratio caused a large amount of generated $\mathrm{Fe}(\mathrm{OH})_{3}$, which damaged the specimen structure by expansive force. As shown in Figure 3, the corrosion products invaded the interior of the concrete after the steel reinforcement passivation film was destroyed, which resulted in the surface of steel reinforcement in the whole bonding section being enwrapped with $\mathrm{Fe}(\mathrm{OH})_{3}$.

Figure 12(b) shows a large number of dense cotton balls (globular) inside the concrete, signifying the formation of corrosion products. A large number of corrosion cracks occurred upon the internal point of the specimens. The steel reinforcement corrosion developed from the center to the surface, while the freeze-thaw damage developed from the surface to the center. Thus, the internal zones of the specimens were the most seriously damaged portions. After 200 freeze-thaw cycles, a greater amount of corrosion products was present in corroded specimens compared with uncorroded specimens. This was because the pores inside the concrete samples increased gradually with increased freezethaw cycles. The structure also became loose, which resulted in the acceleration of chloride ions transport and then the acceleration of steel reinforcement corrosion. A large number of corrosion products were accumulated in the cracks caused by freeze-thaw damage, which resulted in the expansion of cracks and the spalling of the concrete layer. In summary, the deterioration process of concrete involves an increasing number of macro pores and expansion of micro cracks under the action of freeze-thaw cycles and steel reinforcement corrosion. In general, the deterioration process of concrete is the process of increasing the number of macro pores, decreasing the number of micro pores, and gradual expansion of micro cracks.

\section{Discussion}

The degradation mechanism of concrete with fitting analyses of micro and macro indices under different freeze-thaw conditions are herein discussed. The relationships between the porosity and corrosion ratio and the porosity and bond strength were obtained, further verifying the effect of freezethaw cycles on the corrosion of the reinforced concrete.

4.1. The Relationship between Corrosion Ratio and Porosity. In order to get reliable test results, samples were analyzed after 23.4 days (12\% theoretical corrosion ratio) to determine the relationship between the porosity of the concrete edge points and the actual corrosion ratio under different freezethaw cycles, with the results shown in Figure 13.

Figure 13 shows a nonlinear correlation between porosity and corrosion ratio with different numbers of freezethaw cycles. The correlation was greater than 0.9 , providing a coefficient to approximately evaluate the corrosion behavior of reinforced concrete under different freeze-thaw conditions. The actual corrosion ratio increased with porosity because the width and quantity of cracks increased with more freeze-thaw cycles. At the micro level, the freeze-thaw damage changed the number of connecting holes in concrete and ion transport performance, which accelerating the steel corrosion rate in reinforced concrete. In fact, the change of porosity had a significant effect on the actual corrosion ratio with the increases of corrosion times. Thus, for the reinforced concrete with initial damage, the longer the corrosion time, the greater the deviation of the theoretical corrosion ratio under the same porosity.

4.2. The Relationship between Bond Strength and Porosity. From the microstructure analysis, the increase of porosity led to increased ion transport, which accelerated the chemical corrosion of the reinforced concrete. In order to study the effect of freeze-thaw cycles on the bond behavior of reinforced concrete, $23.4 \mathrm{~d}$ samples $(12 \%$ theoretical corrosion ratio) were chosen to analyze the relationship between the porosity of the concrete edge points and the bond strength under different freeze-thaw cycles. These results are shown in Figures 14 and 15.

Figure 14 shows a quadratic function correlation between the porosity and the pull-out force with different freeze-thaw cycles. In addition, when the porosity was less than $20 \%$, the ultimate pull-out force changed only slightly. However, when the porosity was greater than $20 \%$, the ultimate pull-out force decreased rapidly. When analyzing the pull-out tests (Figure 7), the pull-out form of steel reinforcement changed from a splitting failure to a pulling failure with increasing numbers of freeze-thaw cycles. After repeated freeze-thaw cycles, the micro cracks in the interior and numerous capillary pores increased. The path of chloride ions and sulfate ion flow was formed by those cracks. 

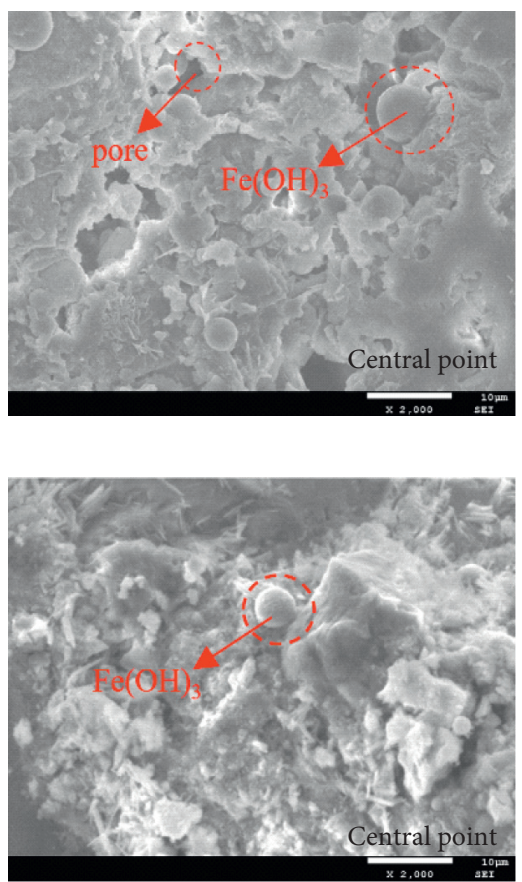

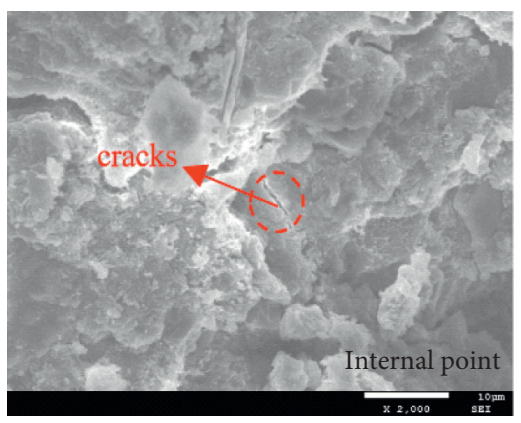

(a)

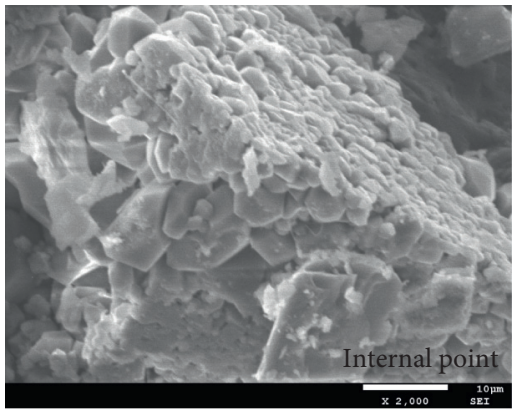

(b)
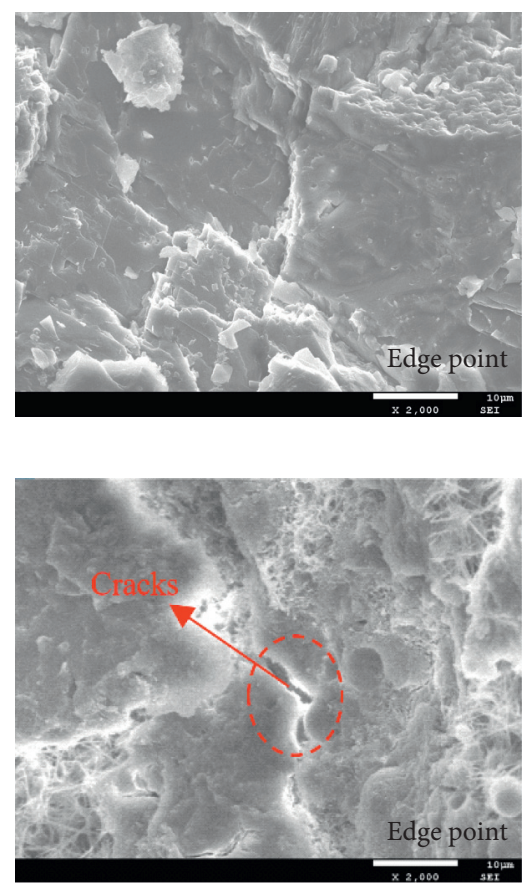

FIgURE 12: Electron microscope scans of $12 \%$ theoretical corrosion ratio. (a) 0 cycles of freeze-thaw with $12 \%$ corrosion group. (b) 200 cycles of freeze-thaw with $12 \%$ corrosion group.

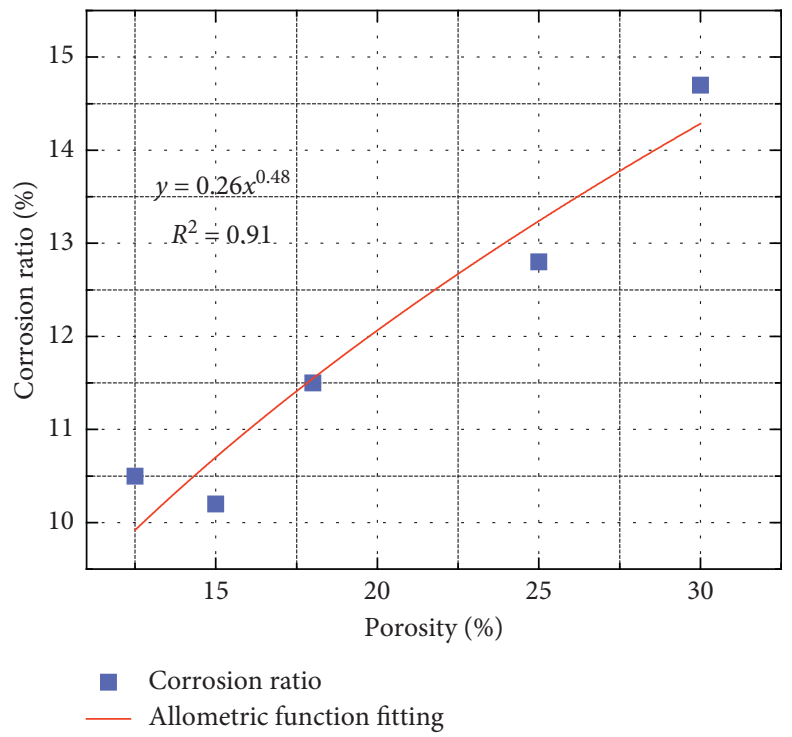

FIGURE 13: The relation between porosity and corrosion ratio.

Thus, the strength of concrete will gradually reduce and the concrete will damage due to corrosion expansive pressure caused by steel reinforcement corrosion destroying the layer of concrete. The porosity especially increased with increasing numbers of freeze-thaw cycles.

Figure 15 shows that porosity is negatively correlated with bond slippage, wherein the bond slippage decreased by $6.9 \mathrm{~mm}$ after increasing porosity from 0.13 to 0.28 . This is because the higher number of freeze-thaw cycles and greater steel reinforcement corrosion increased the deterioration rate of bond behavior in the reinforced concrete. Due to the rapid development of macro cracks caused by the heterogeneous porosity distribution from surface to center, the surface peeling was much more serious after more freezethaw cycles. Freeze-thaw damage changed the porosity and ion transport properties, which led to the decrement of the bond slippage and destruction of concrete. In general, when the number of freeze-thaw cycles was small, the effect of 


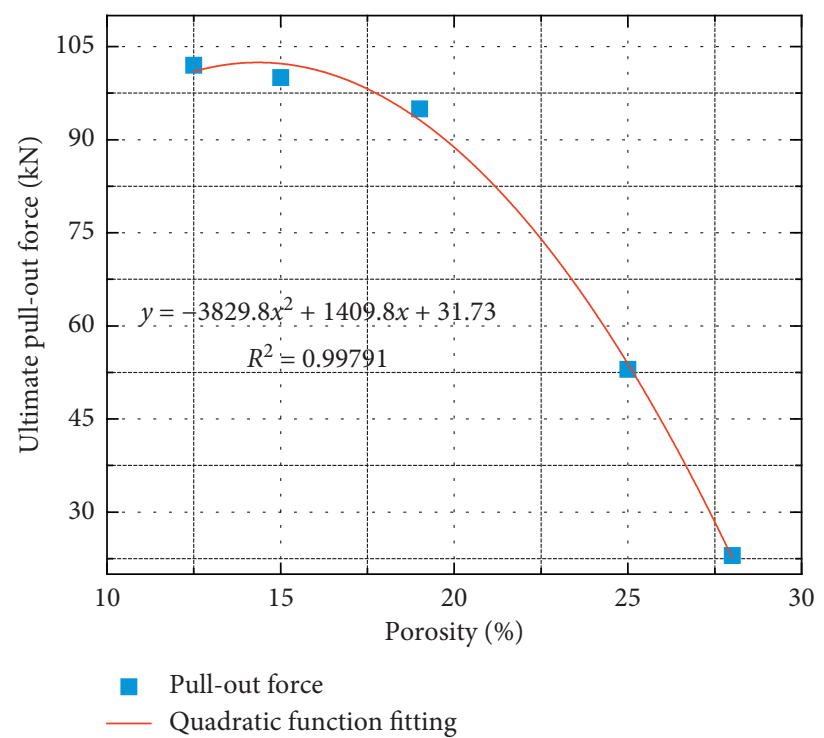

FIgURE 14: The relationship between porosity and ultimate pull-out force.

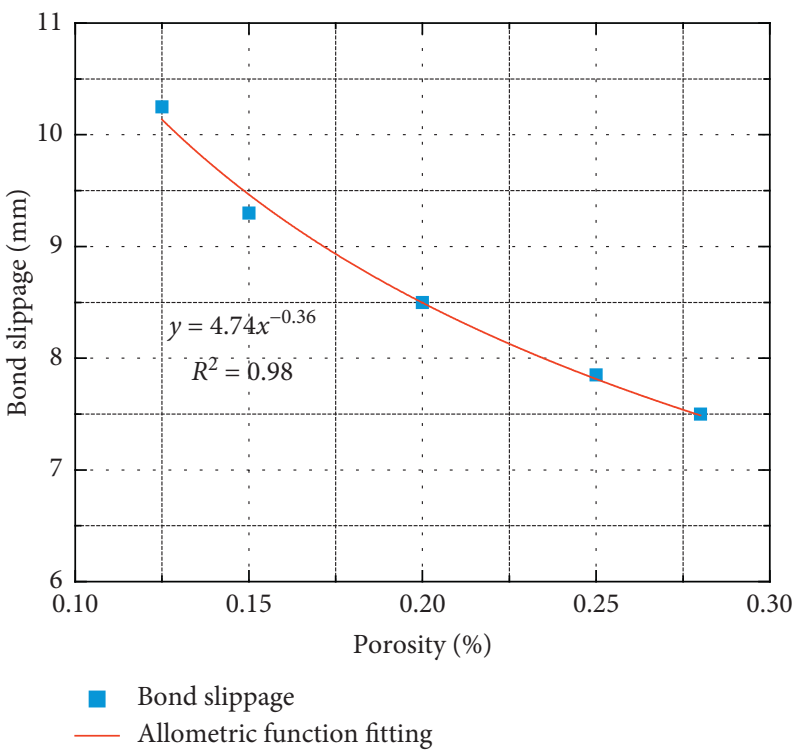

FIGURE 15: The relationship between porosity and bond slippage.

freeze-thaw and corrosion on the bond properties of reinforced concrete depended on the combined action of freezethaw cycles and corrosion. In contrast, when the number of freeze-thaw cycles reached 200 cycles, the effect of freezethaw and corrosion on the bond properties of reinforced concrete mainly depended on the action of freeze-thaw cycles.

\section{Conclusion}

The effect of freeze-thaw damage on steel reinforcement corrosion was investigated by accelerated corrosion experiments under different freeze-thaw cycles, and the evolutions of macro parameters and microstructure were obtained. The results of this study are summarized in the following concluding remarks.

(1) The surface state of specimens showed obvious change after 100 freeze-thaw cycles, and expansive cracks with large widths could be seen after $23.4 \mathrm{~d}$ of corrosion (12\% theoretical ratio). Also, the corrosion mass and corrosion rate of steel reinforcement increased by $39.6 \%$ and $39.7 \%$ when comparing 200 freeze-thaw cycles to 0 cycles, respectively.

(2) The ultimate pull-out force and bond slippage decreased with increasing numbers of freeze-thaw cycles. However, the rate decrease varied with different corrosion times. When the corrosion time reached $23.4 \mathrm{~d}$ (12\% theoretical corrosion ratio), the 
pull-out force of 200 freeze-thaw cycles decreased by $73 \%$ compared with 0 freeze-thaw cycles. The bond slippage decrease after 200 freeze-thaw cycles was $31 \%$ of the 0 -cycle value.

(3) The relationship between macroscopic mechanical properties and microscopic porosity structure indicated that the effect of freeze-thaw on steel reinforcement corrosion manifested in two aspects: first, freeze-thaw damage increased porosity, which led to a decrease in concrete strength; second, freeze-thaw damage accelerated the steel reinforcement corrosion rate, decreasing the bonding properties of the concrete.

(4) The difference between the theoretical corrosion ratio and actual corrosion ratio increased with increased numbers of freeze-thaw cycles, and the influence of freeze-thaw and corrosion on the bond properties of concrete gradually led to degradation of the concrete strength, which was dominated by freeze-thaw cycles.

\section{Data Availability}

The raw/processed data required to reproduce these findings cannot be shared at this time as the data also form part of an ongoing study.

\section{Conflicts of Interest}

The authors declare that they have no conflicts of interest.

\section{Acknowledgments}

This work was financially supported by the Educational Commission of Hubei Province of China (no. Q20201203), National Natural Science Foundation of China (no. 52009068), and National Natural Science Foundation of China (no. 51879145).

\section{References}

[1] C. A. Apostolopoulos and V. G. Papadakis, "Consequences of steel corrosion on the ductility properties of reinforcement bar," Construction and Building Materials, vol. 22, no. 12, pp. 2316-2324, 2008.

[2] F. P. Glasser and K. K. Sagoe-Crentsil, "Steel in concrete: Part II Electron microscopy analysis," Magazine of Concrete Research, vol. 41, no. 149, pp. 213-220, 1989.

[3] W. Zhou, G. Ma, and C. Hu, "Long-term deformation control theory of high concrete face rockfill dam and application," in Proceedings of the Asia-Pacific Power and Energy Engineering Conference, Wuhan, China, March 2011.

[4] J. A. González, S. Feliú, P. Rodríguez, E. Ramírez, C. Alonso, and C. Andrade, "Some questions on the corrosion of steel in concrete-Part I: when, how and how much steel corrodes," Materials and Structures, vol. 29, no. 1, pp. 40-46, 1996.

[5] A. C. Houlsby, "Discussion of "Progress in Rockfill Dams" by J. Barry cooke (October, 1984)," Journal of Geotechnical Engineering, vol. 112, no. 2, pp. 226-227, 1986.
[6] A. Neville, "Chloride attack of reinforced concrete: an overview," Materials and Structures, vol. 28, no. 2, pp. 63-70, 1995.

[7] S. Yoon, K. Wang, W. J. Weiss, and S. P. Shah, "Interaction between loading, corrosion, and serviceability of reinforced concrete," ACI Structural Journal, vol. 97, pp. 637-644, 2000.

[8] T. Zhang, X. Lyu, H. Liu, L. Zhang, J. Wang, and S. Gao, “Axial performance degradation of squared CFST stubs in severe cold and acid rain area," Construction and Building Materials, vol. 262, 2020.

[9] H. Ma and F. Chi, "Technical progress on researches for the safety of high concrete-faced rockfill dams," Engineering, vol. 2, no. 3, pp. 332-339, 2016.

[10] W. Zhou, S. Li, Z. Zhou, and X. Chang, "Remote sensing of deformation of a high concrete-faced rockfill dam using InSAR: a study of the Shuibuya dam, China," Remote Sensing, vol. 8, no. 3, p. 255, 2016.

[11] Y. Wang, Y. Cao, P. Zhang et al., "Water absorption and chloride diffusivity of concrete under the coupling effect of uniaxial compressive load and freeze-thaw cycles," Construction and Building Materials, vol. 209, pp. 566-576, 2019.

[12] A. F. a. Abubakar, X.-B. Zuo, S. Zou, O. O. Ayinde, and A. M. Aliyu, "Electrochemical investigation on the influence of sulfates on chloride-induced corrosion of steel bar in cement-based materials," Journal of Sustainable Cement-Based Materials, vol. 9, no. 2, pp. 112-126, 2020.

[13] Y. Lv, W. Zhang, F. Wu, H. Li, Y. Zhang, and G. Xu, "Influence of initial damage degree on the degradation of concrete under sulfate attack and wetting-drying cycles," International Journal of Concrete Structures and Materials, vol. 14, Article ID 119903, 2020.

[14] Y.-S. Yoon, J.-P. Won, S.-K. Woo, and Y.-C. Song, "Enhanced durability performance of fly ash concrete for concrete-faced rockfill dam application," Cement and Concrete Research, vol. 32, no. 1, pp. 23-30, 2002.

[15] T. C. Powers, "A working hypothesis for further studies of frost resistance of concrete," Journal of the American Concrete Institute, vol. 41, pp. 245-272, 1945.

[16] M. Pigeon, Durability of Concrete in Cold Climates, Taylor \& Francis Group, Abingdon, UK, 2014.

[17] X. Li, "Analysis on causes and countermeasures of concrete highway bridge typical disease," Urban Architects, no. 18, p. 221, 2013.

[18] P. Pei, S. Zheng, Y. Zhang, and L. Dong, "Overview on the bonding of reinforced concrete under pristine, corrosive and freeze-thaw conditions," Journal of Adhesion Science and Technology, vol. 33, no. 7, pp. 761-789, 2019.

[19] Z. Ma, T. Zhao, J. Xiao, and T. Guan, "Evaluation of rebar corrosion in reinforced concrete under freeze-thaw environment and protection measures," Anti-Corrosion Methods and Materials, vol. 63, no. 2, pp. 128-136, 2016.

[20] Z. Wang, Q. Zeng, L. Wang, Y. Yao, and K. Li, "Corrosion of rebar in concrete under cyclic freeze-thaw and Chloride salt action," Construction and Building Materials, vol. 53, pp. 40-47, 2014.

[21] C. G. Berrocal, K. Lundgren, and I. Löfgren, "Corrosion of steel bars embedded in fibre reinforced concrete under chloride attack: state of the art," Cement and Concrete Research, vol. 80, pp. 69-85, 2016.

[22] W. Zhang, Y. Pi, W. Kong et al., "Influence of damage degree on the degradation of concrete under freezing-thawing cycles," Construction and Building Materials, vol. 260, Article ID 119903, 2020. 
[23] X. Ji, Y. Song, and Y. Liu, "Effect of freeze-thaw cycles on bond strength between steel bars and concrete," Journal of Wuhan University of Technology, vol. 23, no. 4, pp. 584-588, 2008.

[24] H. Wang, S. He, X. Yin, and Z. Cao, "Experimental study on fatigue performance of reinforced concrete beams in corrosive environment with cyclic loads," Structural Durability \& Health Monitoring, vol. 14, no. 2, pp. 95-108, 2020.

[25] K. Liu, J. Yan, X. Meng, and C. Zou, "Bond behavior between deformed steel bars and recycled aggregate concrete after freeze-thaw cycles," Construction and Building Materials, vol. 232, Article ID 117236, 2020.

[26] Y. Zhang, H. Liu, R. Tong, and J. Ren, "Effect of nano silica on freeze-thaw resistance of cement-fly ash mortars, cured in corrosive condition at different temperature," Cement, Wapno, Beton, vol. 24, no. 2, pp. 137-153, 2019.

[27] E. Sicat, F. Gong, T. Ueda, and D. Zhang, "Experimental investigation of the deformational behavior of the interfacial transition zone (ITZ) in concrete during freezing and thawing cycles," Construction and Building Materials, vol. 65, pp. 122-131, 2014.

[28] X. Yao, M. Zhang, J. Guan, L. Li, W. Bai, and Z. Liu, "Research on the corrosion damage mechanism of concrete in two freeze-thaw environments," Advances in Civil Engineering, vol. 2020, Article ID 8839386, 11 pages, 2020.

[29] T. Luo, C. Zhang, X. Xu, Y. Shen, H. Jia, and C. Sun, "Effects of cyclic freeze-thaw on the steel bar reinforced new-to-old concrete interface," Molecules, vol. 25, no. 5, p. 1251, 2020.

[30] GB 1499.2-2007, Steel for the Reinforcement of Concrete, Part II: Hot Rolled Ribbed Bars, General Administration of Quality Supervision, Inspection and Quarantine of the People's Republic of China, Beijing, China, 2007, in Chinese.

[31] DL/T 5016-1999, Design Code for Concrete Face Rockfill Dams, China Renewable Energy Engineering Institute, Beijing, China, 1999, in Chinese.

[32] T. Gonen, S. Yazicioglu, and B. Demirel, "The influence of freezing-thawing cycles on the capillary water absorption and porosity of concrete with mineral admixture," KSCE Journal of Civil Engineering, vol. 19, no. 3, pp. 667-671, 2015.

[33] GB/T 50082-2009, Standard for Test Methods of Long-Term Performance and Durability of Ordinary Concrete, Ministry of Construction of the People's Republic of China, Beijing, China, 2009, in Chinese.

[34] R. Liu, L. Jiang, J. Xu, C. Xiong, and Z. Song, "Influence of carbonation on chloride-induced reinforcement corrosion in simulated concrete pore solutions," Construction and Building Materials, vol. 56, pp. 16-20, 2014.

[35] Y. Cheng, Y. Zhang, Y. Jiao, and J. Yang, "Quantitative analysis of concrete property under effects of crack, freezethaw and carbonation," Construction and Building Materials, vol. 129, pp. 106-115, 2016.

[36] GB/T 50152-2012, Standard for Test Method of Concrete Structure, Ministry of Housing and Urban Rural Development of the People's Republic of China, Beijing, China, 2012, in Chinese. 